\title{
COUNTERPOINT REVOLUTIONIZED
}

\section{By HERBERT SANDERS}

I

F you ask a theoretical student why he studies counterpoint he will probably tell you he does so for examination purposes: if you question him as to wherein lies the intrinsic value of the study he will promptly tell you "it is invaluable as discipline." Exempting candidates for diplomas and degrees from the counting, it is safe to assert that but few study counterpoint for its own sake and it is not wide of the mark to suggest that the number of candidates for degrees would be considerably larger were it not for the imposed tests in counterpoint. The chief objection to its serious study is not its difficulty but its alleged uselessness.

Color is given to this belief by the fact that treatises on counterpoint are contradictory in many important points so that students are ignorant as to what authoritative counterpoint really is, and, what is more annoying still, to find after years of patient study of the tenets they evolved by comparison of conflicting theories that in actual composition many of its rules are entirely disregarded.

The standard writers on the subject have helped to give currency to these beliefs. In the preface to his "counterpoint" Macfarren says:

Its study is of the utmost value, as giving to one who has musical ideas facility in their expression. It is an exercise of the musician's mind as useful for developing the power of thought and the ability to control it as is any mechanical exercise for developing muscular strength and other physical resources.

\section{Prout says:}

..... the value of the strict mental discipline involved in working with limited resources cannot be overestimated. One of the strongest arguments in favor of this study is the fact that no composer has ever attained the highest eminence without first submitting himself to its restraints.

So much for the 'discipline' idea. Without labouring the point it must suffice to add that nearly all modern writers believe the intrinsic value of strict counterpoint to lie in mental discipline.

In regard to the relaxation of the rules of strict counterpoint in actual composition Ouseley wrote: "The rules are never followed in all their rigour in the works of the best composers." Mac- 
farren states: "The rules of Counterpoint were established prior to the discovery of the natural principles whereon harmony, and the phraseology that springs from it, are based." Sir A. Mackenrie says: "It is generally admitted that the study of counterpoint has been hampered by a good many rules which have absolutely no application at all in the extended domain of modern music," et cetera. If, then, the highest appeal for the study of strict counterpoint be that it is good 'discipline,' and if it be authoritatively acknowledged that its restrictions are not of practical application, why study it? Cannot such discipline be obtained in some less irritating way?

Before answering the question it is necessary to define what strict countorpoint really is. As a matter of fact there are three distinct schools of strict counterpoint:

(1) The OLD SCHOOL, Fux, Féti, Albrechtberger, Cherubini, Ouseley, Bridge, etc.

(q) The MACFARREN SCHOOL, Macfarren, Prout, Pearce, etc.

(3) The MODERN FREE SCHOOL as taught in Germany and France.

Prof. Bridge says he regrets that modern authors are departing in theory from the principles and practice of the older contrapuntists, but he does not say why he prefers the Old School.

The main tendency of the Macfarren School is the restriction of harmonic resource and the extension of melodic resource. In the Modern Free School the restrictions of the early theorists are removed, with music, not rubbish, as the result. It will be remembered by many that some years ago when a controversy as to what really constituted strict counterpoint troubled the minds of some English students they sent to Rheinberger for some specimens. On arriving in England these specimens were shown to a prominent musician who exclaimed "Why, this isn't Counterpoint; it's music." In a lecture before the Royal College of Organists, Kitson said:

We often see in examples by men who follow the old school, things done which are due to a want of time perspective. Little things creep in that show at once that they are not sure of their ground. The abstract view of counterpoint leads some to see the evolution of the art of counterpoint, progressing with the art of music as a whole, in which by degrees all the cramping restrictions of the early theorists are removed and culminating in the MUSIC, not the counterpoint of Rheinberger.

Until we have one school instead of three, and until counterpoint is regarded as something more than an artificial and abstract study, it will be impossible to avoid controversy on the matter. Nor must it be viewed entirely from the aesthetic stand- 
point for it would then be regarded as artistic or inartistic according to the varying standard of taste of the individual or period. For counterpoint to have the moral support of an unanimity of opinion and uniformity of practice it must be regarded only secondarily from the abstract and aesthetic side and primarily from the historic.

But if the historic counterpoint be taught, what period? What composer or group of composers? To these questions there is but one answer, no other has been suggested. Dickinson says ("Music in the Western Church"):

Melody as we know it is the peculiar endowment of the Italians, and Palestrina, a typical son of Italy, crowned the Netherland science with ethereal grace of movement which completed once for all the four hundred year's striving of contrapuntal art, and made it stand forth among the artistic creations of the Middle Age perhaps the most divinely radiant of them all.

\section{Sir Hubert Parry ("Style in Musical Art") writes:}

Palestrina affords the most perfect examples of pure choral style. In his work the development of many centuries is summed up; and practically he stands alone in scope and artistic resourcefulness.

Here then in Palestrina we have the basis for a treatise on counterpoint which will settle for all time the divergencies of contrapuntal theorists. But to be of exact value his practice must be summarised and adapted to the modern scalic system-a procedure to which no ultilitarian can reasonably object. The questions touching the use of the harmonic or melodic scale and modulation we need not discuss at this point.

As far as I am aware no modern writer has based his treatise on counterpoint absolutely on Palestrina with the exception of Dr. C. H. Kitson ("Art of Counterpoint," Oxford), and I may state, that we have in this volume the study of counterpoint revolutionized and its tenets based on a foundation strong as Gibraltar. In short Dr. Kitson has given to the world a treatise at once historical, logical, and practical. Let us briefly, led by Dr. Kitson, consider a few of the restrictions and non-restrictions of the later theorists in the light of Palestrina.

(a) Most theorists allow one chord in a bar. Those who permit two chords in a bar look on it somewhat as a "concession to the weaker brethren'. Yet Palestrina freely uses two chords in a bar. Kitson points out that the prohibition of two chords in bar was due to the misconception that each whole-note represents one chord whereas the contrapuntal principle is not that of writing 
two notes to one chord but two notes to one NOTE. In combined counterpoint the use of $t$ wo chords in a bar is often an absolute necessity if the harmony is to be smooth and the species is to maintain its conjunct nature. One chord in a bar often makes combined counterpoint an impossibility. (As a bar of scholastic counterpoint represents two accents, a strong and weak, Palestrina's bars represent two bars of scholastic counterpoint). Dr. Kitson is rightly severe on the Macfarren School for encouraging a wrong attitude of mind in allowing such a progression as the following to be considered as one chord in a bar (i.e. the treble $\mathbf{E}$ regarded as a passing note) whereas the MENTAL IMPRESSION is strongly that of two chords:

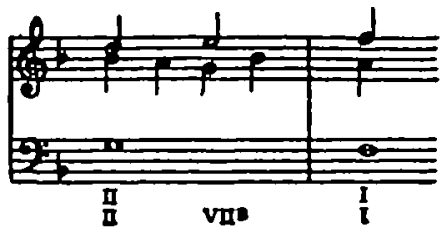

(b) Modern writers prohibit the use of the 8 chord.

As a matter of fact there is no more cause for complaint in modern practice than in the ineffective use made of the $\$$ chord. Professor Buck in his "Unfigured Harmony" advises the student to avoid the chord until he is accustomed to use 'edged tools.' (Though how he will learn to use it by avoiding it I am unable to comprehend). Harmony books are no help in the matter; look at Jadassohn for instance:

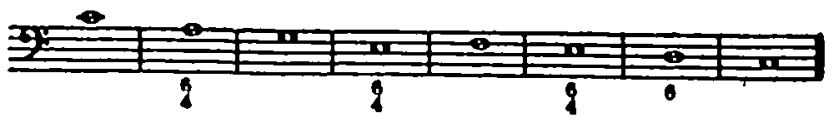

Such a progression as:

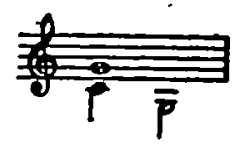

Macfarren would regard as a common chord followed by its second inversion. But Kitson points out that Palestrina could not possibly have regarded it in that light because the "Art of Counterpoint" belongs to a period before the term 'chord' was known. He says:

Combinations were framed according to the principles of consonance and dissonance and the consonances were the 1st, 3rd, 5 th, and 8th, 
and in three or more parts the perfect or augmented fourth and the diminished 6th may occur between the upper parts if each is concordent with the bass or lowest part.

And in order to understand the principles of Historic Counterpoint it is essential that we form the habit of looking at it in this contrapuntal light, though not exclusively so.

We are now in a position to consider the conditions under which Palestrina used the $\%$ chord. Says Kitson:

A modern would analyse the following passage according to the figuring:

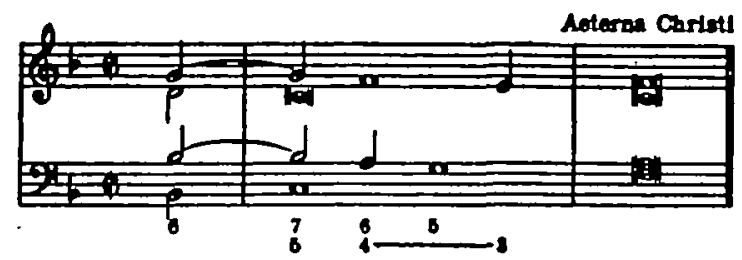

The bass (c) is a point d'orgue (pedal point). In the tenor the 7th (B flat) after preparation resolves on the concord (A). The fifth in the treble moves with it, forming a sirth, the tenor being regarded as the real bass. Again Palestrina uses what we call a 6 with the fourth prepared, the rest being concordant requires no such preparation:

Palestrina. Kyrie-Iste Confessor

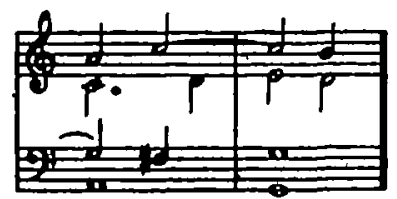

No one, of course, blue pencils i resulting from the use of unessential notes:-

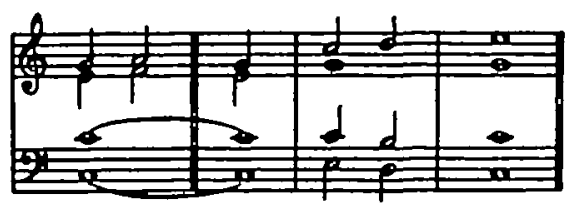

The following travesty of the truth would be amusing if it were not serious. A prominent theorist, being told the 1 must not be used in strict counterpoint, and not knowing the real truth was that what was forbidden was not what we term the \&, nor its mental effect, but the unprepared fourth, argued thus:-

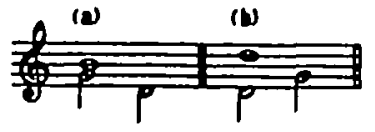


(a) bad: mental effect of 8

(b) good, VI'b : V (key C).

In the music of the period both are technically correct. From an absolute point of view (a) is far better than (b). Thus the student is being told to avoid what is correct in the period, and also being told to choose instead something that is infinitely inferior as music. $A$ student trained on historic principles will never in practical work use the sir-fours and essential discords crudely because he has in this technique the origin of all our rules for the treatment of sir-fours and fundamental discords. School

(c) Prepared discords-allowed by all but the Macfarrén

The application of contrapuntal analygis will show the use of prepared discords:

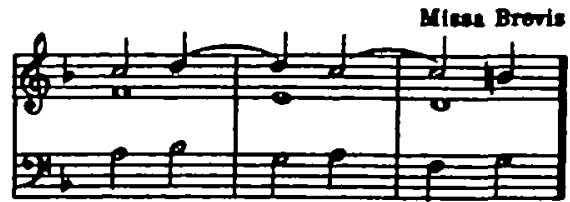

on which our author comments:

It must be borne in mind that any classification of the vertical chords is entirely foreign to the horizontal system, and that no prepared discord bears any relation to the essential harmony, that is, it demands no consideration except that it move one step downward into consonance.

Ignoring the discord the following is the contrapuntal analygis:

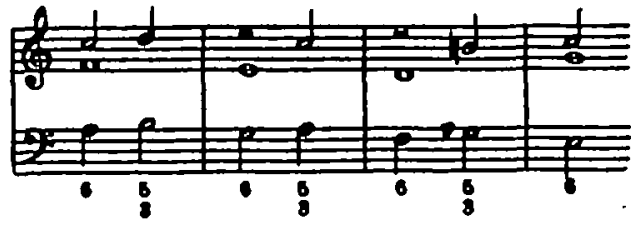

(d) Eighth notes, dotted quarters, leap of 6th.

The varying opinion regarding the use of these are settled by Palestrina. Quavers may be used on the ind and 4th quarter note of a bar, but dignity alone forbids their use on both beats on the same bar. To quote Kitson:

There are in Palestrina isolated examples of the use of four eight notes in succession. The rarity of such a procedure justifies its exclusion from_the regular technique of the period-

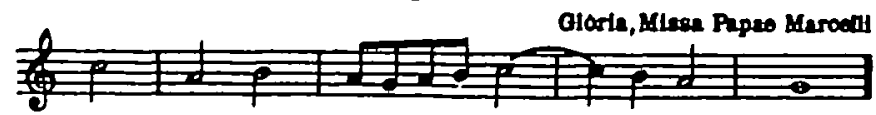


Dotted quarter-notes, involving the use of a single eighth-note

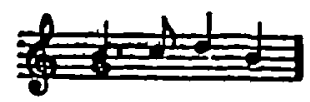

form no part of the technique of the period and are therefore wrong from the historic- not absolute-point of view.

The dotted quarter note is generally used by students of counterpoint to avoid a difficulty. The avoidance of the interval of a sixth in quarter notes, the melodic restrictions as to diminished intervals, the leap of the third followed by a sirth and other controversial melodic questions can be solved by a study of Palestrina for, as Professor Wooldridge says:

The governing principle, technically speaking, of Palestrina's melody is of course that of conjunct movement; this, however, is beautifully varied by the constantly changing value of the notes, and also by occasional disjunct intervals, which are permitted upon the condition of not continuing in the direction of the leap, but immediately returning by gradual motion towards the point of departure.

This rule may also, of course, be deduced from the methods of Pales-

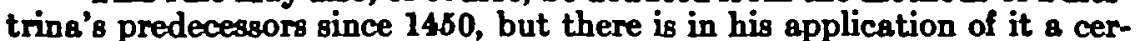
tain final elegance, representing the ideal in such matters, which have been aimed at generally hitherto, but was now for the first time attained.

In this connection the words of Sir C. V. Stanford are worth quoting:

..... teachers often overlook the natural tendency of a young and inventive brain to chafe under advise which at the moment seems merely formal, irksome and dry. The impatience of temperament cannot be curbed merely by dogmatic insistence on the rules themselves; it can only be moulded and brought into line by the sympathetic method of explaining why these rules were laid down and by clearly showing their origin. In counterpoint, for instance, a beginner who is conversant with the developments of modern music cannot be expected to understand a rule which "forbids" a skip from

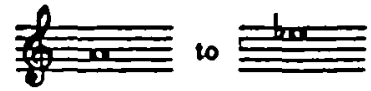

in a part which professes to be a melody written to fit another melody. But when it is explained to him that this rule was made in the early times for music written for the unaccompanied human voice, an instrument which possesses no mechanical means for hitting a note as the piano has, and which finds great difficulty in producing diminished and augmented intervals with accurate intonation, he will begin at once to appreciste that such a rule is founded, not for the purpose of providing materials for examination papers, but on the principles of common sense. 
There are certain progressions possible which, while correct according to modern treatises and so frequently found in students' efforts should from the harmonic point of view be impossible:
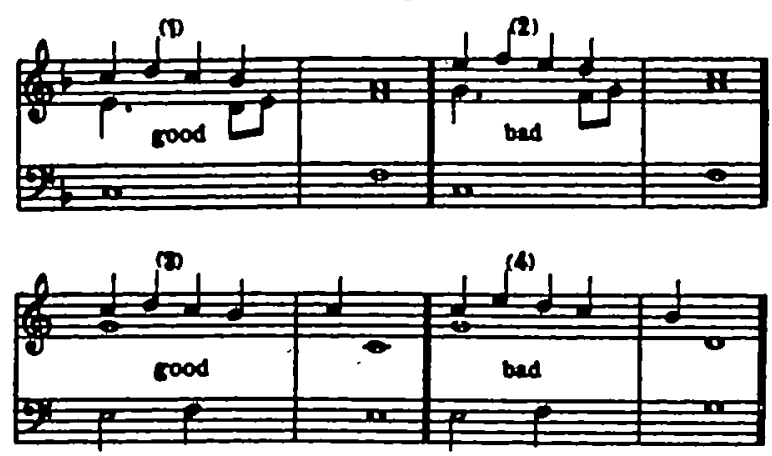

How is it that 2 and 4 are unsatisfactory in effect? Simply, as Dr. Kitson, points out, because the harmonic link between the bars is ignored. Such crudities as:

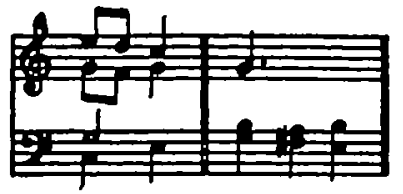

are safeguarded by the following rule:

Whenever two parts move in parallel thirds or sixths by conjunct degrees (the first combination being essential and the second unessential), they should proceed in parallels till they reach essential harmony, unless the bass be a pedal-

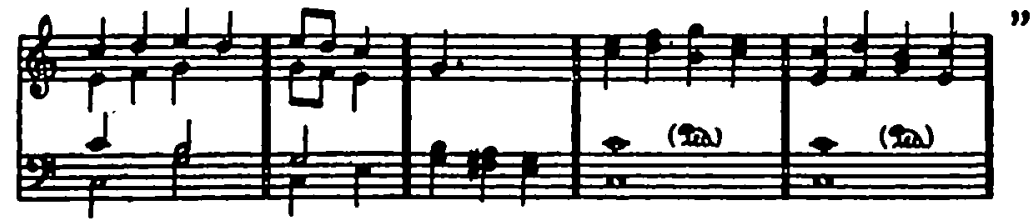

It is obvious that rules which permit such inartistic progressions in combined counterpoint as the following (quoted by Kitson) require revolutioniring:
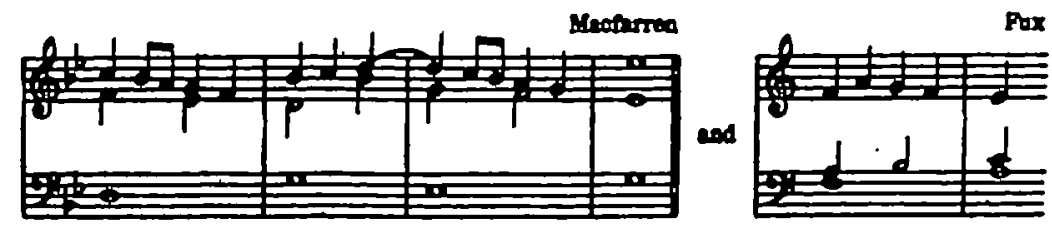
By insisting on a smooth harmonic connection of consecutive harmonies Dr. Kitson brings the theory and practice of combined counterpoint into a position at once artistic, serviceable and logical.

The following use of a dotted quarter note followed by an eighth note $d . d d$ is against ancient theory and practise. It is really a way of dodging the striking of a discord which is an effort to avoid what Palestrina never did avoid.

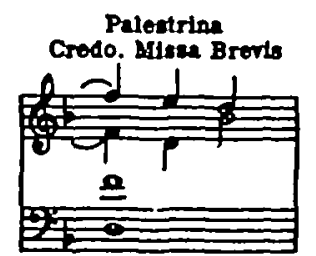

In striking a discord by conjunct and contrary motion we get the origin of the appoggiatura-

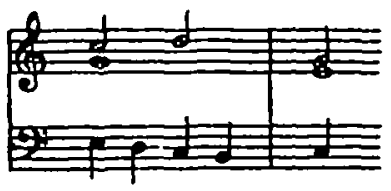

Of these collisions, says Rockstro, the greatest of the masters took no notice whatever. Provided their florid parts moved well with the bass, they cared nothing for the crashes which took place between them. Without taking undue license in this regard it will be readily seen that its introduction makes musical counterpoint a possibility. And surely the death knell of the barren and unfruitful counterpoint as generally understood is due to be rung! How can a system which leads to such rubbish as the following:
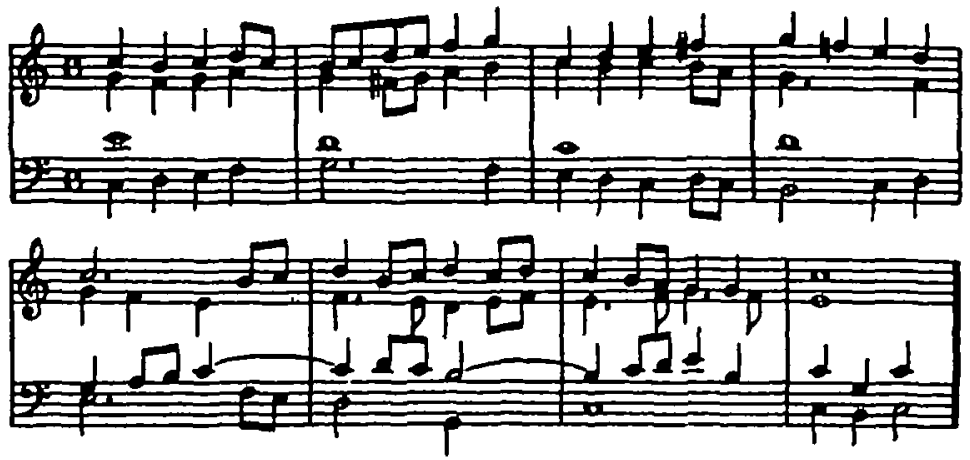

justify its existence? 
But the fault does not invalidate the study of strict counterpoint-such results are due to the teaching of the many writers on the subject who have grafted their own peculiar ideas on to previous writers and their misconception so that we have strayed far from the fountain head of what pure counterpoint is. But the study of historic counterpoint as expounded by Kitson results in music and not mechanical rubbish, it enables the student to preserve the characteristics of each species in melodic curve, it forms the door through which modern harmony is reached, it shows the student where to change his harmony and feel his rhythm, it rests on the authority of practice and not on the caprice of theory, moreover it does not end in a cul-de-sac for its principles can be extended in modern work and "the evolution of modern harmony from them is as natural as the growth of a tree's foliage from its stem."

In conclusion I will give Dr. Kitson's ides of strict counterpoint in his own words (lecture before the Royal College of Organists):

The principles of strict counterpoint rightly understood are not arbitrary or meaningless: the fundamental principles of music remain good for all time, and you cannot alter them, you cannot tinker them. $\AA$ system of counterpoint which is based on a perversion of these principles must lead to disaster, a statement which I have had proved to me time after time. Let me urge you then to an intelligent study of the subject, read some meaning into it, and see in it all the fundamentals upon which the whole scheme of the present day is framed and amplified. So you will find your harmony enlightening your counterpoint and when you come to study modern composition you will have nothing to unlearn, but you will find what resource you have at your disposal is not the result of the entire rejection of the principles of strict counterpoint, but is merely a logical extension of them. Your contrapuntal study will not only give you the power of combining graceful melodies, it will have formed in you a foundation in harmonic resource, which, because it is true, lies at the very root of all further progress. The art of music as far as technique is concerned is not the history of a series of experiments each antagonistic to the other: methods of diction may vary, but the sum total of resource which is used for these ends is the result of an evolution which has its foundation in the principles which have guided composers since the birth of combined sound and which found their first culmination in the works of Palestrina.

Dr. Kitson's further treatise, "Applied Strict Counterpoint," shows how the principles he has formulated lead to composition in the strict style, that is, in the style of the Polyphonic Period. Here the student has the goal of his strict contrapuntal study, and he will see that it is not the meaningless rubbish he has conceived it to be. 